Check for updates

Cite this: RSC Adv., 2019, 9, 30685

Received 8th August 2019

Accepted 20th September 2019

DOI: 10.1039/c9ra06166e

rsc.li/rsc-advances

\section{Dual-functional SiOC ceramics coating modified carbon fibers with enhanced microwave absorption performance $\uparrow$}

\author{
Sifan Zeng, ${ }^{\text {ab }}$ Wanlin Feng, ${ }^{\text {a }}$ Shuyuan Peng, ${ }^{\mathrm{c}}$ Zhen Teng, ${ }^{\mathrm{a}}$ Chen Chen, ${ }^{\mathrm{a}}$ \\ Haibin Zhang ${ }^{*}{ }^{* a}$ and Shuming Peng (D) ${ }^{* a}$
}

\begin{abstract}
Multi-functional carbon fiber (CF) based composites have great potential as new-type microwave absorption materials (MAMs). However, it was still a huge challenge to integrate antioxidation and MA properties into CF based composites. Herein, the SiOC ceramics coating modified carbon fibers (SiOC/ CFs) were prepared by a polymer precursor pyrolysis method. The X-ray photoelectron spectroscopy (XPS) revealed that the $\mathrm{SiOC}$ coating was composed of $\mathrm{SiOC}, \mathrm{SiO}_{2}$, and amorphous carbon phases. The $\mathrm{SiOC}$ ceramics as dual-functional coating not only heightened the oxidation temperature from $415^{\circ} \mathrm{C}$ to $890^{\circ} \mathrm{C}$, but also highly improved the microwave absorbing ability from $-12.60 \mathrm{~dB}$ to $-47.50 \mathrm{~dB}$. The enhanced MA performance could be attributed to multiple reflections in the cross-linked structure, various polarization relaxation processes, and the favorable impedance matching effect. The SiOC ceramics coating as a semiconductor could suppress the skin effect originating from the cross-linked CF network, thus leading to a favorable impedance matching behavior.
\end{abstract}

\section{Introduction}

Microwave absorption materials (MAMs) have attracted considerable attention around the world for their extensive applications in commercial and military domains. ${ }^{1-3}$ In general, MAMs could be classified into magnetic and dielectric loss materials. ${ }^{4}$ Although magnetic loss materials as typical MAMs showed excellent MA properties, their applications had been restricted by their high density and poor oxidation resistance properties, such as $\mathrm{Fe}, \mathrm{Co}, \mathrm{Ni}$, and their oxides. ${ }^{5,6}$ While carbon materials as dielectric loss absorbers were widely investigated for MA responses owing to their light weight, excellent chemical stability, and high electronic conductivity, such as carbon black, carbon fibers, carbon nanotubes, and graphene etc. ${ }^{2,7-9}$ For example, Chen et al. reported that graphene foam exhibited an optimal reflection loss (RL) of $-33.2 \mathrm{~dB}$ around $13 \mathrm{GHz}$ and an effective absorption bandwidth (EAB, RL < $-10 \mathrm{~dB})$ in the range of $4-18 \mathrm{GHz} .^{10} \mathrm{Fu}$ et al. presented that the porous CFs showed a bandwidth of $\mathrm{RL}<-5 \mathrm{~dB}$ covering the whole X-band (8.2-12.4 GHz). ${ }^{7}$ Thus, it could be concluded that carbon materials would be promising and lightweight candidates for

\footnotetext{
Innovation Research Team for Advanced Ceramics, Institute of Nuclear Physics and Chemistry, China Academy of Engineering Physics, Mianyang, 621900, China

${ }^{b}$ Department of Engineering and Applied Physics, University of Science and Technology of China, Hefei, 230026, China.E-mail: hbzhang@caep.cn; pengshuming@caep.cn

'Department of Product Design, School of Art \& Design, Dalian Polytechnic University, Dalian, 116034, China
}

$\dagger$ Electronic supplementary information (ESI) available. See DOI: 10.1039/c9ra06166e
MAMs. Additionally, in order to meet the requirements for practical applications, MAMs were also demanded to overcome the bottlenecks of physical and chemical stability. ${ }^{11}$ However, the poor oxidation resistance properties of carbon materials would severely limit their universal applications, especially in high-speed aircraft. Therefore, it would be expected to develop a lightweight, and stable microwave absorbing candidate for practical applications.

Silicon-based ceramics had been widely studied as anti-oxidation coating owing to their low density, good chemical stability, and superior mechanical properties. For example, Rahul et al. deposited a $\beta$-SiC coating on carbon fiber (CF) by a plasma enhanced chemical vapor deposition (CVD) method. ${ }^{12} \mathrm{~S}$. Masoudifar et al. prepared a $\mathrm{SiC}$ coating on graphite flakes through reacting graphite with $\mathrm{Si}$ metal powder in molten salts. ${ }^{13}$ Niu et al. prepared the SiOC modified carbon bonded with CFs by precursor impregnation and pyrolysis method using dimethoxydimethylsilane and methyltrimethoxysilane as precursors. ${ }^{14}$ Zhou et al. reported that $\mathrm{BN} / \mathrm{SiC}$ coating modified CFs via dip-coating and CVD processes showed an optimal RL value of $-13.3 \mathrm{~dB}$ and a EAB of $2.6 \mathrm{GHz} .{ }^{15}$ Cao et al. prepared short $\mathrm{CF} /$ silica composites with an optimal RL value of $-10.22 \mathrm{~dB}$ at $9.9 \mathrm{GHz} .{ }^{16}$ Among these silicon-based ceramics, SiOC materials were considered as promising MA candidates owing to their lightweight, oxidation resistance, chemical and physical stability, and controllable structure. ${ }^{17,18}$ Particularly, relying on the carbon component, the SiOC materials possessed a higher electrical conductivity than that of $\mathrm{SiC}$, thus resulting in a better electronic dipole polarization loss performance. ${ }^{19}$ However, those strategies not only required complicated processes and conditions, but also showed weak microwave absorbing capability. Above all, it was still 
a challenge to fabricate a dual-functional coating that possessed the antioxidation and MA properties.

In this study, a polymer precursor pyrolysis method was carried out to synthesis the SiOC ceramics coating modified CFs (SiOC/CFs). The SiOC coating not only successfully protected CFs from oxidizing but also improved the microwave absorbing ability. The optimal RL value of SiOC/CFs was $-47.50 \mathrm{~dB}$ at 2.64 $\mathrm{GHz}$, which meant that $99.998 \%$ incident electromagnetic wave could be consumed and converted to thermal energy. The SiOC coating could suppress skin effect originated from cross-linked CFs, which could effectively improve impedance matching behavior. Furthermore, the interfacial polarization between SiOC coating and CFs played an important role in promoting dielectric loss. This facile technique may present a new notion for the refinement of carbon-based MAMs.

\section{Experimental}

The SiOC coating studied in this paper was fabricated from a commercial liquid-phase polysilazane (PSN, Institute of Chemistry, Chinese Academy of Sciences). The carbon fibers (CFs) were obtained by carbonization of electrospun polyacrylonitrile (PAN) fibers precursor. PAN (Sigma-Aldrich)
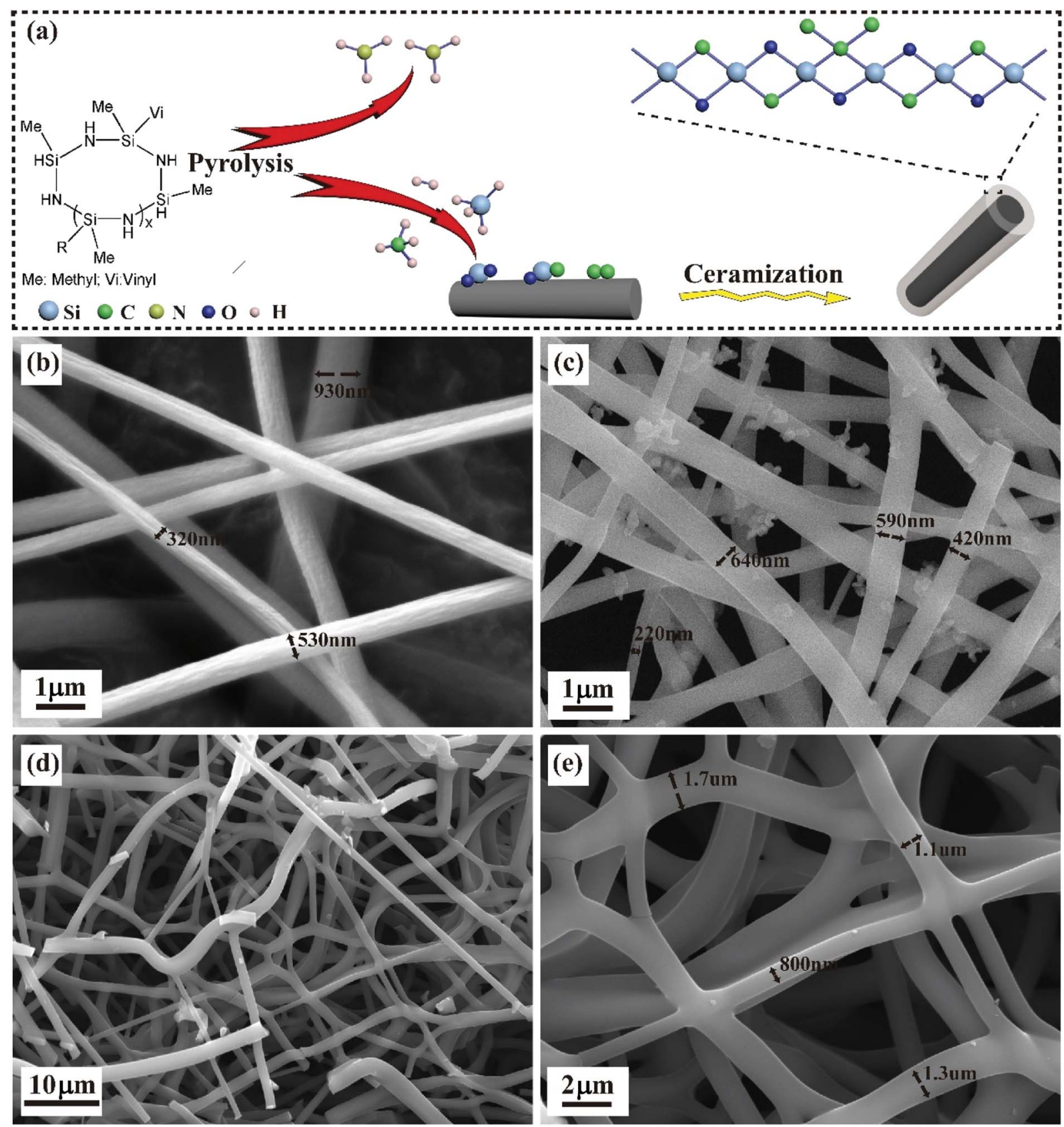

Fig. 1 (a) The schematic representation of the preparation route of SiOC/CFs. The SEM images of (b) PAN fibers, (c) PAN-derived CFs, and SiOC/ CFs at different magnification of $(\mathrm{d}) \times 1.5 \mathrm{k}$ and $(\mathrm{e}) \times 5.0 \mathrm{k}$. 
powder was dissolved in $N, N$-dimethylformamide (DMF, AR, $99.5 \%$, Aladdin) to obtain a $10 \mathrm{wt} \%$ electrospinning solution, and then PAN fibers were prepared by electrospinning at a voltage of $18 \mathrm{kV}$, at last, PAN fibers fabric was collected on an aluminum foil. To stabilize the fiber morphology, pre-oxidation was carried out at $280{ }^{\circ} \mathrm{C}$ under air atmosphere. The precursor PSN and PAN fibers were placed into two $\mathrm{Al}_{2} \mathrm{O}_{3}$ boats respectively and then delivered inside a quartz tube furnace. The temperature of the furnace was ramped to $1000{ }^{\circ} \mathrm{C}$ at a heating rate of $5{ }^{\circ} \mathrm{C} \mathrm{min}{ }^{-1}$ for $2 \mathrm{~h}$ under a flowing argon (Ar) atmosphere (purity 99.99\%, flowing rate $2 \mathrm{~L} \mathrm{~min}^{-1}$ ), and then cooled to the room temperature naturally with flowing $\mathrm{Ar}$ atmosphere. Finally, the black products were collected without any further purification. As a comparison, CFs were prepared using the same heating procedure without PSN.

The morphology of the products was observed using a field emission scanning electron microscopy (SEM, MX2600FE). The structures were examined using Raman spectroscopy (RM-1000, Renishaw) and X-ray photoelectron spectroscopy (XPS, VG Multilab 2000, Thermo Electron Corporation). Thermogravimetric and differential thermal analysis (TG-DTA) was recorded on a NETZSCH STA $449 \mathrm{C}$ under ambient atmosphere. The electromagnetic parameters of samples were measured at 2-18 GHz using Vector network analyzer (N5245A, Agilent) in a wax matrix with $50 \%$ loading. The products were homogeneously mixed with wax, and then the products/wax composites were pressed into a toroidal mold (inner diameter of $3.04 \mathrm{~mm}$, outer diameter of $7 \mathrm{~mm}$ ). After mold release, the measured toroidalshaped samples were obtained. The reflection loss, RL (dB) of the samples were calculated by our self-programmed software using the data of complex permeability and permittivity.

\section{Results and discussion}

Fig. 1a depicted the synthesis process of CFs coated by SiOC ceramics. The organic functional groups of PSN were interaction, rearrangement, and recombination occurred in the pyrolysis process from 200 to $700{ }^{\circ} \mathrm{C} .{ }^{20}$ The ammonia $\left(\mathrm{NH}_{3}\right)$ was released because of the transamination reaction at a temperature from 200 to $400{ }^{\circ} \mathrm{C}^{21}$ With the increase of temperature, hydrogen $\left(\mathrm{H}_{2}\right)$, silane $\left(\mathrm{SiH}_{4}\right)$, methane $\left(\mathrm{CH}_{4}\right)$ and a small quantity of ethylene $\left(\mathrm{C}_{2} \mathrm{H}_{4}\right)$ and acetylene $\left(\mathrm{C}_{2} \mathrm{H}_{2}\right)$ were liberated due to the scissions of $\mathrm{C}-\mathrm{C}, \mathrm{Si}-\mathrm{C}, \mathrm{Si}-\mathrm{H}$, and $\mathrm{C}-\mathrm{H}$ bonds at 400$700{ }^{\circ} \mathrm{C}^{22}$ Furthermore, a small fraction of $\mathrm{SiH}_{4}, \mathrm{CH}_{4}, \mathrm{C}_{2} \mathrm{H}_{4}$, and $\mathrm{C}_{2} \mathrm{H}_{2}$ could be pyrolyzed, and then deposited on PAN fibers. ${ }^{23} \mathrm{It}$ was notable that $\mathrm{C}-\mathrm{O}-\mathrm{C}, \mathrm{C}=\mathrm{O}$ could be formed within cyclized PAN in the oxidative stabilization process. At the same time, PAN-derived CFs were carbonized under $\mathrm{Ar}, \mathrm{SiH}_{4}$, and $\mathrm{CH}_{4}$ atmosphere. Therefore, the interactions and reactions of $\mathrm{Si}-\mathrm{H}$, $\mathrm{C}-\mathrm{H}, \mathrm{C}-\mathrm{C}$ bonds, and oxygen functional groups could form $\mathrm{C}-$
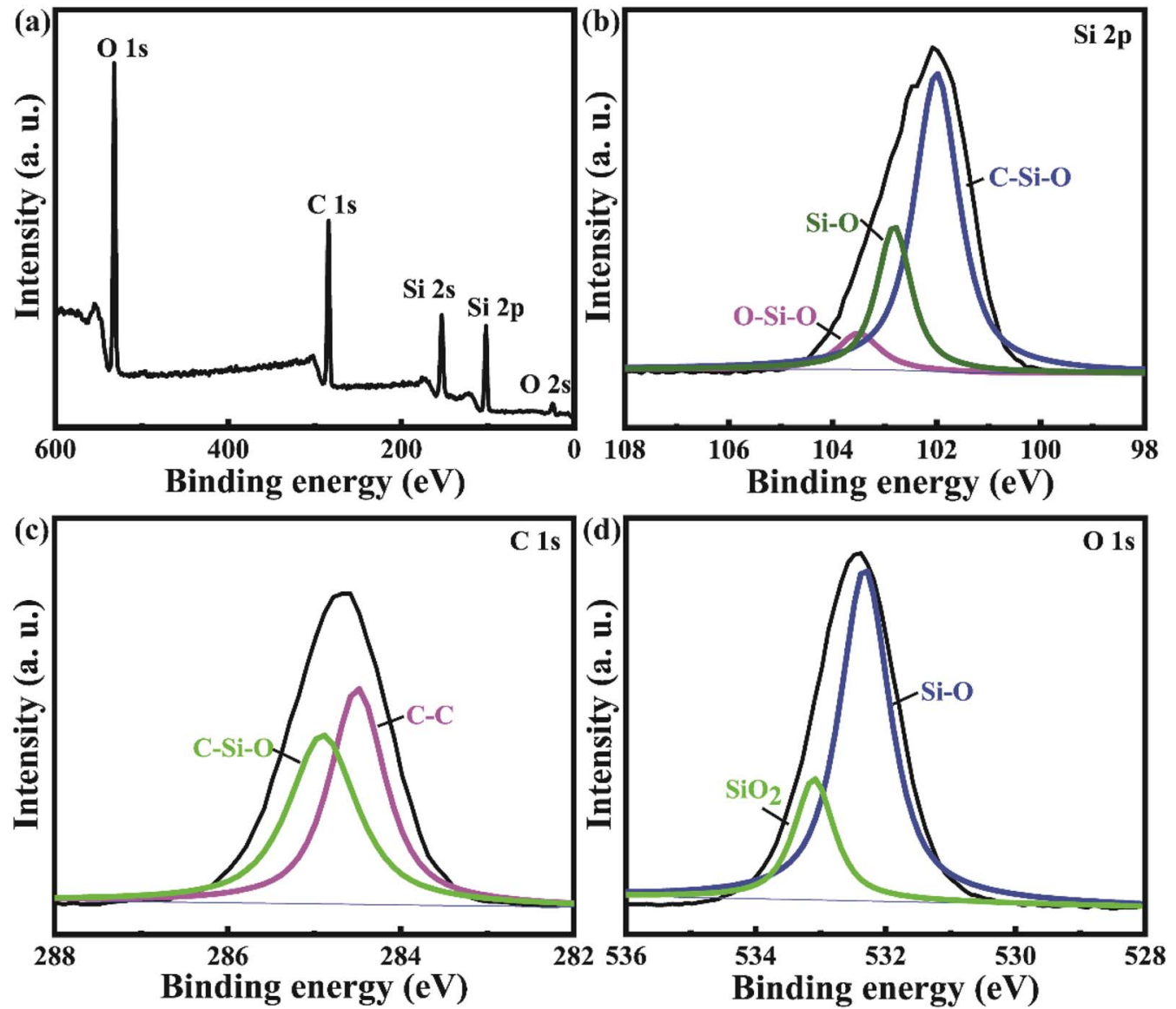

Fig. 2 XPS spectra of full range scanning for SiOC/CFs composites: (a) survey spectrum; (b) Si 2p peak; (c) C 1s peak; and (d) O 1s peak. 
$\mathrm{Si}-\mathrm{O}, \mathrm{O}-\mathrm{Si}-\mathrm{O}$ and $\mathrm{C}-\mathrm{C}$ bonds on the surface of CFs. Finally, the SiOC/CFs composites were developed after the stabilization and ceramization of SiOC, $\mathrm{SiO}_{2}$ and amorphous carbon. The probable reactions were proposed in eqn (S1)-(S4) (ESI $\dagger$ ).

As shown in Fig. 1b, PAN fiber exhibited a typical circular morphology. The crude surface was owing to the evaporation of DMF solvent. These PAN fibers showed inhomogeneous size with a diameter in the range of 320-600 $\mathrm{nm}$. The damp air induced static would deteriorate unstable voltage in the electrospinning process, so PAN fibers may become inhomogeneous because of the mutative and erratic electric force. In addition, these fibers lied randomly and formed a cross-linked network structure. Fig. 1c displayed PAN-derived CFs with the diameter of 220-600 $\mathrm{nm}$ corresponding to the volume shrinkage of PAN during carbonization process. ${ }^{24}$ The continuous CFs coated by SiOC ceramics were shown in Fig. 1d. The high magnification given in Fig. 1e displayed smooth fibers with the diameter of $0.8-1.7 \mu \mathrm{m}$.

The XPS spectra (Fig. 2) were carried out to ascertain the composition of SiOC/CFs products. As shown in Fig. 2a, the survey spectrum revealed that the SiOC coating was composed of $\mathrm{Si}, \mathrm{O}$, and $\mathrm{C}$ elements with a ratio of $1: 1.2: 1.7$. Fig. $2 \mathrm{~b}$ displayed the broad Si band (for Si 2p) and revealed the presence of different valence around $\mathrm{Si}$ atom arising from bonding with other elements, it could be deconvoluted into three bands around at 101.98, 102.88 and $103.48 \mathrm{eV}$, corresponding to C-Si$\mathrm{O}, \mathrm{Si}-\mathrm{O}$ and $\mathrm{O}-\mathrm{Si}-\mathrm{O}$ bonds respectively. ${ }^{25}$ The analysis of the fitted $\mathrm{C}$ 1s band (Fig. 2c) suggested the emergence of peaks located at $\mathrm{C}-\mathrm{C}(284.48 \mathrm{eV})$ and $\mathrm{C}-\mathrm{Si}-\mathrm{O}(284.88 \mathrm{eV})$ bonds. ${ }^{26}$ The chemical shift toward to a higher bonding energy of $284.88 \mathrm{eV}$ responded a bonding configuration of $\mathrm{C}-\mathrm{Si}-\mathrm{O}$, this was because the electronegative of $\mathrm{O}$ atom was higher than those of $\mathrm{C}$ and $\mathrm{Si}$ atoms. The spectrum of $\mathrm{O} 1 \mathrm{~s}$ given in Fig. $2 \mathrm{~d}$ showed two fitting peaks at 532.38 and $533.08 \mathrm{eV}$ related to $\mathrm{Si}-\mathrm{O}$ and $\mathrm{SiO}_{2}$ bonds.

The Raman spectra of SiOC/CFs and CFs given in Fig. 3a were performed to confirm the existence of carbon. Two obvious peaks observed at 1340 and $1580 \mathrm{~cm}^{-1}$ were corresponding to D and $\mathrm{G}$ bands, indicating the graphitic structure. The $\mathrm{G}$ band originated from in-plane stretching of $\mathrm{sp}^{2}$ bonds, such as $\mathrm{C}-\mathrm{C}$ bonds, and the $\mathrm{D}$ band was contributed to disorder graphite phase. ${ }^{26}$ It could be observed that the Raman shift of $\mathrm{G}$ band of SiOC/CFs was higher than that of CFs, this was because that $G$ band of SiOC/CFs composites could be divided into $G, D_{2}$ and $\mathrm{D}_{3}$ bands (Fig. 3b). The fitted $\mathrm{G}$ band of SiOC/CFs composites was located at $1577 \mathrm{~cm}^{-1}$, which was close to that of CFs. The D or $\mathrm{D}_{1}, \mathrm{D}_{2}$ bands were ascribed to disorder graphite lattice $\left(A_{1 \mathrm{~g}}\right.$ symmetry and $E_{2 \mathrm{~g}}$ symmetry respectively), while $\mathrm{D}_{3}$ band originated from amorphous soot. ${ }^{27}$

The TG-DTA were performed to investigate the thermal stability of SiOC/CFs and test the antioxidation function of SiOC coating. Fig. 3c showed the TG-DTA curves of SiOC/CFs products heated from room temperature to $1100{ }^{\circ} \mathrm{C}$ with a rate of $10{ }^{\circ} \mathrm{C}$ min under flowing air. The broad endothermic peak in the range of $30-350{ }^{\circ} \mathrm{C}$ showed that a weight loss about $7 \%$ was corresponding to the
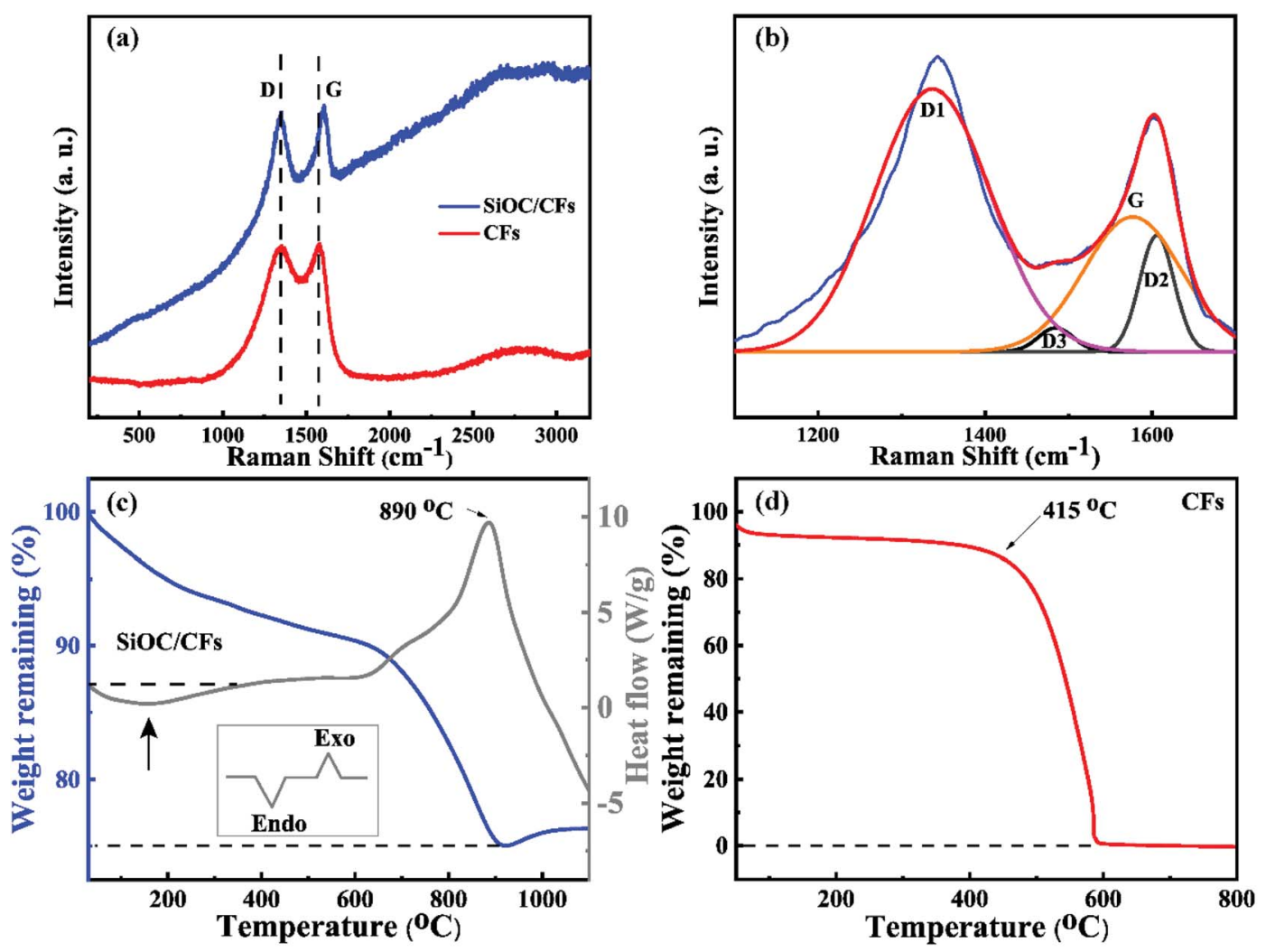

Fig. 3 (a) The Raman spectra of SiOC/CFs and CFs, and (b) Raman spectrum of SiOC/CFs from 1100 to $1700 \mathrm{~cm}^{-1}$. The TG-DTA curves of (c) $\mathrm{SiOC/CFs} \mathrm{composites} \mathrm{and} \mathrm{(d)} \mathrm{CFs} \mathrm{under} \mathrm{air.}$ 
removal of water, and it was considered as a physical process. The exothermic peak occurred at $890{ }^{\circ} \mathrm{C}$ illustrated that a weight loss was about $15 \%$ in the temperature from 620 to $920{ }^{\circ} \mathrm{C}$. And this weight loss was attributed to the oxidation of bulk amorphous carbon in the coating and exposed CFs (exothermic reactions). The weight increased a little starting at $920{ }^{\circ} \mathrm{C}$, because the oxidation of C-Si phase could form $\mathrm{SiO}_{2}$ with a heavier molecular mass. Fig. 3d displayed the TG curve of CFs. It could be observed that CFs delivered the starting oxidation temperature at $415^{\circ} \mathrm{C}$ and had been totally combusted at $600{ }^{\circ} \mathrm{C}$. Based on the result of TG-DTA data, it revealed that the $\mathrm{SiOC/CFs}$ composites presented a better antioxidation property, moreover, and the SiOC coating could availably protect CFs from oxidizing at $415{ }^{\circ} \mathrm{C}$ and make CFs attractive for use in the high-temperature field.

To evaluate the microwave absorbing efficiency of SiOC/CFs composites, the reflection loss (RL) of the electromagnetic wave was calculated by the following eqn (1) and (2).

$$
\begin{aligned}
& Z_{\text {in }}=Z_{0}\left(\mu_{\mathrm{r}} / \varepsilon_{\mathrm{r}}\right)^{1 / 2} \tanh \left[j(2 \pi f d / c)\left(\mu_{\mathrm{r}} / \varepsilon_{\mathrm{r}}\right)^{1 / 2}\right] \\
& \mathrm{RL}=20 \log \left|\left(Z_{\text {in }}-Z_{0}\right) /\left(Z_{\text {in }}+Z_{0}\right)\right|
\end{aligned}
$$

$\varepsilon_{\mathrm{r}}$ was the relative complex permittivity, $\mu_{\mathrm{r}}$ was the complex permeability, $f$ was the frequency of microwave, $d$ was the thickness of the absorber, $c$ was the velocity of the electromagnetic wave in free space, $Z_{\text {in }}$ was the input impedance of the absorber, and $Z_{0}$ was the impedance of air. ${ }^{28}$
According to the eqn (2), the RL value below $-10 \mathrm{~dB}$ revealed that $90 \%$ EM energy was attenuated and absorbed, furthermore, it was an effective and important parameter for evaluating the microwave absorption properties. As shown in Fig. 4a, the optimal RL of SiOC/CFs could reach $-47.50 \mathrm{~dB}$ at $2.64 \mathrm{GHz}$ with a thickness of $5.1 \mathrm{~mm}$, and the $\mathrm{EAB}$ was obtained in the frequency of $2.2-3.4 \mathrm{GHz}$ with a thickness of $3.7-6.0 \mathrm{~mm}$ and 6.8-14.8 GHz with a thickness of $1.3-3.0 \mathrm{~mm}$. In Fig. $4 \mathrm{~b}$, the optimal RL of $-12.60 \mathrm{~dB}$ for CFs was observed at $13.8 \mathrm{GHz}$ with a thickness of $1.0 \mathrm{~mm}$, and the EAB was from 13.1 to $14.3 \mathrm{GHz}$ in the range of thickness from 0.9 to $1.1 \mathrm{~mm}$. There was no doubt that the optimal RL value and effective bandwidth of composites had evidently improved a lot compared to those of CFs, especially in S-band $(2-4 \mathrm{GHz})$. It was apparent that the $\mathrm{RL}$ values of SiOC/CFs were much lower than those of CFs in various layer thicknesses (Fig. 4c). Fig. 4d compared the MA performance between the SiOC/CFs and other Si-based CFs composites. ${ }^{15,16,29-31}$ The SiOC/CFs delivered an excellent MA performance among these composites. The detailed data of related references were listed in Table S1.† Above all, the obtained SiOC/CFs composites possessed an enhanced MA ability and would be a promising candidate for high-temperature MAMs.

The complex permittivity was regarded as an important parameter to investigate the MA properties of SiOC/CFs composites, the relative complex permittivity of composites and CFs were given in Fig. 5a. The values of real $\left(\varepsilon^{\prime}\right)$ and
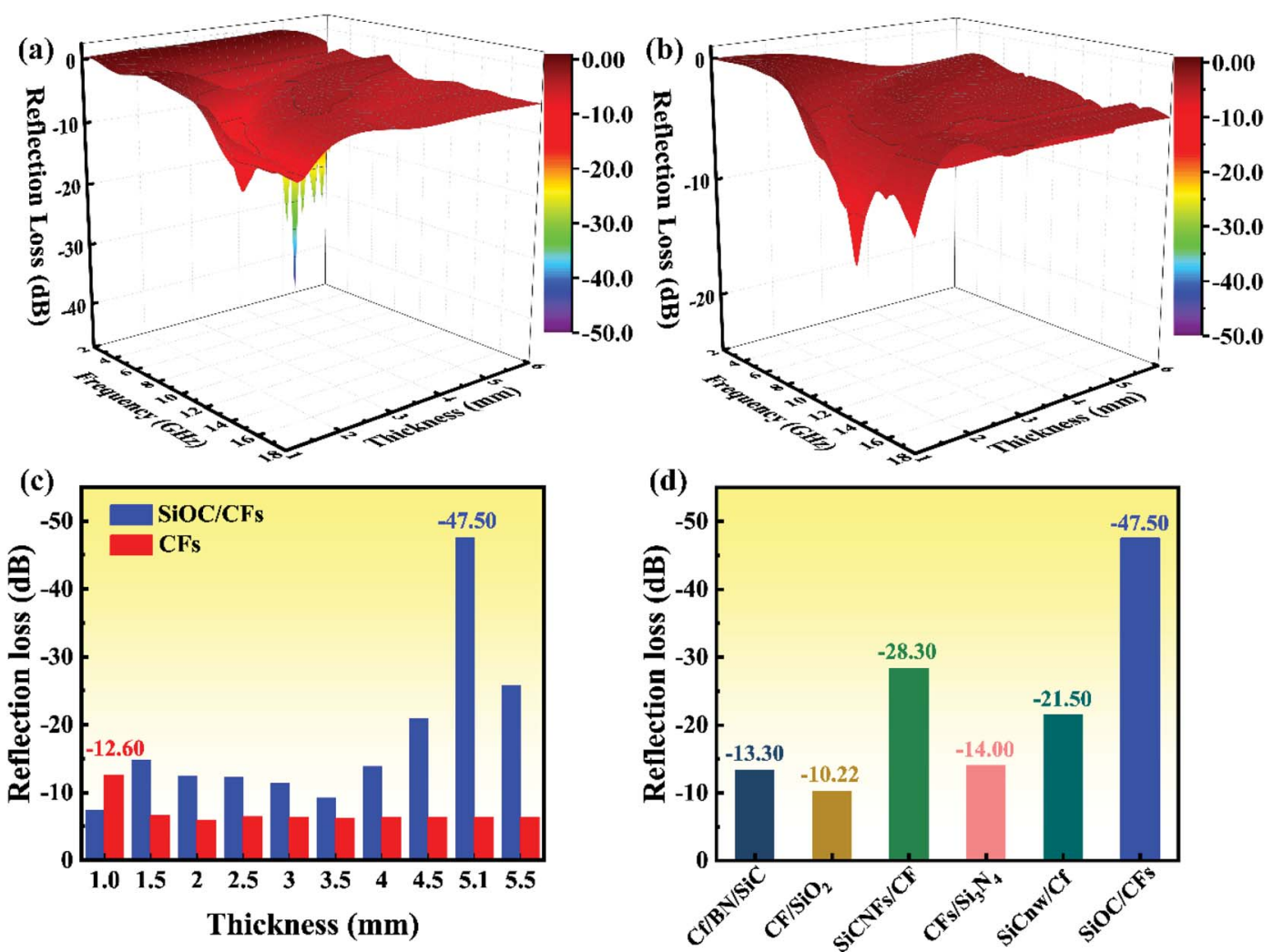

Fig. 4 The three-dimensional microwave RL curves of (a) SiOC/CFs composites and (b) CFs in the frequency range of 2-18 GHz, (c) the optimal $\mathrm{RL}$ values at different layer thicknesses, and (d) the comparison of MA performance of Si-based CFs composites. 
imaginary $\left(\varepsilon^{\prime \prime}\right)$ parts of CFs were higher than those of SiOC/CFs composites. The $\varepsilon^{\prime \prime}$ value was relevant to energy loss because of the rearrangement of electric dipole moment in electromagnetic filed, ${ }^{32}$ the $\varepsilon^{\prime \prime}$ value for two samples showed a decreased trend in the frequency of $2-18 \mathrm{GHz}$. Fig. $\mathrm{S} 1 \dagger$ showed the sketch of band gaps of CFs (conductor) and SiOC composites (semiconductor). The value of the band gap for the conductor was zero, and the SiC had a wide bandgap (2.3-3.4 eV). ${ }^{33}$ On one hand, the smaller band gap would give rise to decreasing Fermi energy, thus electrons at the valence band would be easier to jump into the conduction band, and then be polarization. On the other hand, the cross-linked CFs network formed a good galvanic circle, exacerbating the movement of electrons. The SiOC coating as a semiconductor formed a potential energy barrier between the cross-linked CFs, and the barrier could effectively prevent electrons jumping and migrating. ${ }^{34}$ Consequently, the complex permittivity of SiOC composites was lower than those of CFs. Fig. S $2 \uparrow$ exhibited the tangent loss $(\tan \delta \varepsilon=$ $\left.\varepsilon^{\prime \prime} / \varepsilon^{\prime}\right)$ curves of SiOC/CFs and CFs. The tan $\delta \varepsilon$ values of CFs were higher than those of SiOC products, it meant that CFs created stronger attenuation ability for incident microwave than that of SiOC/CFs products. According to Debye theory, Cole-Cole semicircles ( $\varepsilon^{\prime \prime}$ versus $\left.\varepsilon^{\prime}\right)$ of SiOC/CFs composites and CFs were plotted in Fig. S3† to discuss diversified dielectric loss mechanism, and one semicircle generally implied one relaxation process. $^{35}$ There were seven continuous semicircles appeared for composites as presented in Fig. S3a. $\dagger$ And four semicircles were found for CFs in Fig. S3b. $\uparrow$ On the one hand, SiOC coating could absorb microwave because of the polarization relaxation originated from defects, electrons, and dipoles. Especially, $\mathrm{SiOC}, \mathrm{SiO}_{2}$ and free carbon in amorphous $\mathrm{SiOC}$ coating would result in dipolar polarization. ${ }^{19}$ On the other hand, the existence of interfaces between SiOC coating and CFs brought about interfacial polarization, which could boost the consumption of electromagnetic energy. ${ }^{36,37}$ The amorphous SiOC coating was consisted of $\mathrm{SiOC}, \mathrm{SiO}_{2}$ and free carbon components. Therefore, a large number of grain boundaries within SiOC coating also made great contributions to improving interfacial polarization. ${ }^{38}$ Besides, the inner CFs of composites constructed a good galvanic circle, thus leading to a favorable conduction loss. ${ }^{39,40}$ Thus, there were much more polarization processes within SiOC/CFs composites. Meanwhile, an excellent candidate of MAMs not only possessed high attenuation efficiency but also had good impedance matching. ${ }^{41}$ As shown in Fig. $5 \mathrm{~b}$, the value of normalized input impedance $\left(\left|Z_{\text {in }} / Z_{0}\right|\right)$ for composites was much higher than CFs. When the value of $\left|Z_{\text {in }}\right|$ $Z_{0} \mid$ was equal to 1 , it meant the best impedance matching. As mentioned above, the cross-linked CFs network was propitious
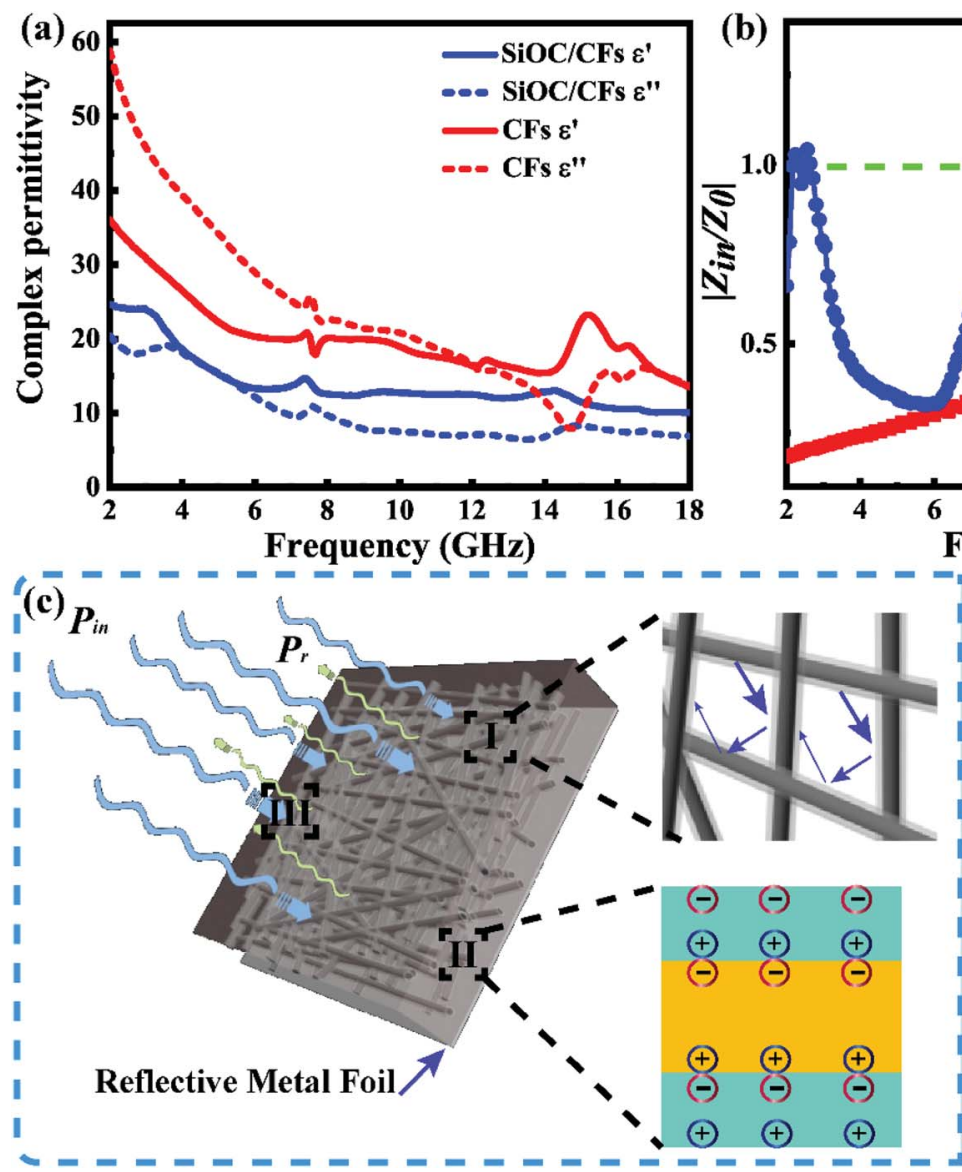

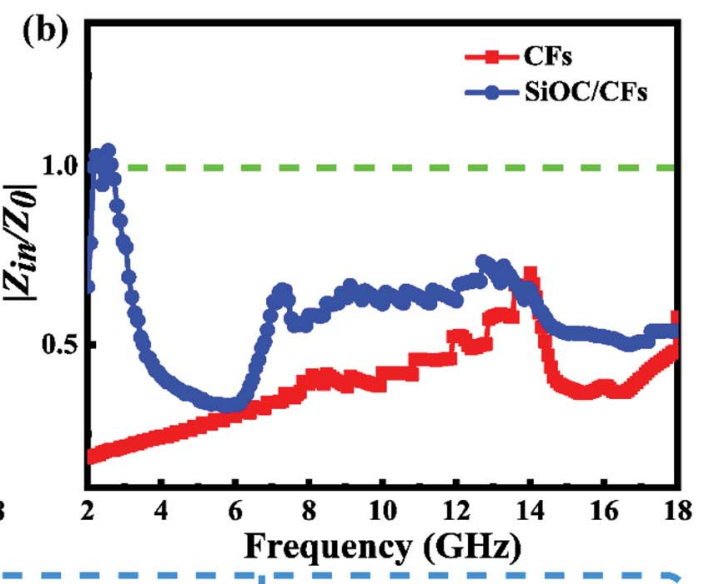

|III: Impedance matching|
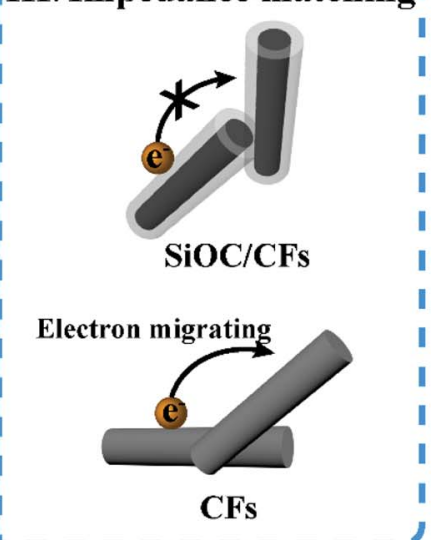

Fig. 5 The measured (a) real and imaginary permittivity, (b) the curves of normalized input impedance $\left(\left|Z_{\text {in }} / Z_{0}\right|\right)$ of SiOC/CFs and CFs. (c) The schematic representation of loss mechanism of the SiOC/CFs composites. 
to the movement of electrons, while the SiOC coating as a barrier suppressed electrons jumping and migrating. Thus, an undesirable reflection occurred onto the surface of CFs due to the skin effect, and the SiOC coating could restrain skin effect originated from CFs, resulting in more microwave propagating into absorber. ${ }^{42}$ Although the tan $\delta \varepsilon$ of CFs was higher than that of SiOC/CFs, the MA performance of SiOC/CFs was much better than that of CFs owing to its better impedance matching.

The schematic representation of microwave absorption mechanism for SiOC/CFs was proposed in Fig. 5c. When incident microwave propagated on SiOC/CFs composites backed with a reflective metal, the incident microwave power $\left(P_{\text {in }}\right)$ would be consisted of two parts, reflected $\left(P_{\mathrm{r}}\right)$ and absorbed $\left(P_{\mathrm{a}}\right)$ microwave power. ${ }^{10} P_{\mathrm{a}}$ was related to the double microwave absorption by SiOC and CFs. $P_{\mathrm{r}}$ was determined by interfacial impedance gap between air and absorber. The loss mechanism of composites was contributed to three parts. Initially, the multiple reflections occurred on fibers could extend routes of electromagnetic wave propagation in the absorber, which was propitious to the loss of microwave. Secondly, the diversified polarization relaxation processes would boost the dielectric loss. Thirdly, the favorable impedance matching would make more microwave propagate into absorber, leading to an enhanced MA performance.

\section{Conclusions}

In summary, the SiOC ceramics coating modified CFs had been successfully synthesized using a one-step precursor pyrolysis technique. The XPS results revealed that the SiOC coating was composed of SiOC, $\mathrm{SiO}_{2}$ and amorphous carbon phases. The SiOC ceramics coating not only effectively protected CFs from oxidizing, but also improved microwave absorbing ability. The optimal RL of composites was $-47.50 \mathrm{~dB}$ at $2.64 \mathrm{GHz}$ with a thickness of $5.1 \mathrm{~mm}$, and the EAB was in the range of 6.8-14.8 $\mathrm{GHz}$ with the thin thickness of 1.3-3.0 $\mathrm{mm}$. The enhanced MA performance could be attributed to multiple reflections in the cross-linked structure, various polarization relaxation processes, especially interfacial polarization, and the enhanced impedance matching effect. The fine antioxidation and MA performance of SiOC/CFs would make it attractive for applying in the high-temperature MA field.

\section{Conflicts of interest}

There are no conflicts to declare.

\section{Acknowledgements}

Haibin Zhang is grateful to the Foundation by the Recruitment Program of Global Youth Experts and the Youth Hundred Talents Project of Sichuan Province. This work is supported by the National Natural Science Foundation of China (Grant No. 91326102), the Science and Technology Development Foundation of China Academy of Engineering Physics (Grant No. 2013A0301012), the Science and Technology Innovation
Research Foundation of Institute of Nuclear Physics and Chemistry.

\section{References}

1 E. Sano and E. Akiba, Carbon, 2014, 78, 463-468.

2 L. Wang, H. Xing, S. Gao, X. Ji and Z. Shen, J. Mater. Chem. C, 2017, 5, 2005-2014.

3 T. Zhang, P. Zhou, B. Xiao, J. Zhang, G. Wen, B. Zhong and L. Xia, Ceram. Int., 2017, 43, 8603-8610.

4 R. Yang, B. Wang, J. Xiang, C. Mu, C. Zhang, F. Wen, C. Wang, C. $\mathrm{Su}$ and Z. Liu, ACS Appl. Mater. Interfaces, 2017, 9, 12673-12679.

5 T. Wu, Y. Liu, X. Zeng, T. Cui, Y. Zhao, Y. Li and G. Tong, ACS Appl. Mater. Interfaces, 2016, 8, 7370-7380.

6 T. Wang, H. Wang, X. Chi, R. Li and J. Wang, Carbon, 2014, 74, 312-318.

7 N. Li, G. W. Huang, Y. Q. Li, H. M. Xiao, Q. P. Feng, N. Hu and S. Y. Fu, ACS Appl. Mater. Interfaces, 2017, 9, 2973-2983.

8 G. Li, T. Xie, S. Yang, J. Jin and J. Jiang, J. Phys. Chem. C, 2012, 116, 9196-9201.

9 S. Zhao, L. Yan, X. Tian, Y. Liu, C. Chen, Y. Li, J. Zhang, Y. Song and Y. Qin, Nano Res., 2017, 11, 530-541.

10 Y. Zhang, Y. Huang, T. Zhang, H. Chang, P. Xiao, H. Chen, Z. Huang and Y. Chen, Adv. Mater., 2015, 27, 2049-2053.

11 W.-L. Song, X.-T. Guan, L.-Z. Fan, Y.-B. Zhao, W.-Q. Cao, C.-Y. Wang and M.-S. Cao, Carbon, 2016, 100, 109-117.

12 R. Pillai, N. Batra, L. M. Manocha and N. Machinewala, Surf. Interfaces, 2017, 7, 113-115.

13 S. Masoudifar, M. Bavand-Vandchali, F. Golestani-Fard and A. Nemati, Ceram. Int., 2016, 42, 11951-11957.

14 M. Niu, H. Wang, L. Su, D. Zhang and J. Shi, Ceram. Int., 2016, 42, 10614-10618.

15 W. Zhou, L. Long, P. Xiao, C.-k. Jia and Y. Li, Surf. Coat. Technol., 2019, 359, 272-277.

16 M.-S. Cao, W.-L. Song, Z.-L. Hou, B. Wen and J. Yuan, Carbon, 2010, 48, 788-796.

17 W. Y. Duan, X. W. Yin, Q. Li, X. M. Liu, L. F. Cheng and L. T. Zhang, J. Eur. Ceram. Soc., 2014, 34, 257-266.

18 B. Du, C. He, J. Qian, M. Cai, X. Wang and A. Shui, J. Am. Ceram. Soc., 2019, 102, 7015-7025.

19 B. Du, C. He, A. Shui, X. Zhang and C. Hong, Ceram. Int., 2019, 45, 1208-1214.

20 Q. Li, X. Yin, W. Duan, B. Hao, L. Kong and X. Liu, J. Eur. Ceram. Soc., 2014, 34, 589-598.

21 S. R. Shah and R. Raj, Acta Mater., 2002, 50, 4093-4103.

22 D. Bahloul, M. Pereira and C. Gerardin, J. Mater. Chem., 1997, 7, 109-116.

23 A. Krause, M. Grube, T. Mikolajick and W. M. Weber, ECS Trans., 2015, 70, 69-78.

24 L. Wang, Y. Yu, P. C. Chen, D. W. Zhang and C. H. Chen, J. Power Sources, 2008, 183, 717-723.

25 X. Zhang, X. Huang, G. Wen, X. Geng, J. Zhu, T. Zhang and H. Bai, Nanotechnology, 2010, 21, 385601.

26 L. David, R. Bhandavat, U. Barrera and G. Singh, Nat. Commun., 2016, 7, 10998. 
27 A. Sadezky, H. Muckenhuber, H. Grothe, R. Niessner and U. Pöschl, Carbon, 2005, 43, 1731-1742.

28 T. Zhang, S. Zeng, G. Wen and J. Yang, Microporous Mesoporous Mater., 2015, 211, 142-146.

29 W. Zhou, L. Long, P. Xiao, Y. Li, H. Luo and R.-m. Yin, Ceram. Int., 2017, 43, 5628-5634.

30 H. Luo, W. Chen, W. Zhou, L. Long, L. Deng, P. Xiao and Y. Li, Ceram. Int., 2017, 43, 12328-12332.

31 R. Wu, Z. Yang, M. Fu and K. Zhou, J. Alloys Compd., 2016, 687, 833-838.

32 H. Sun, R. Che, X. You, Y. Jiang, Z. Yang, J. Deng, L. Qiu and H. Peng, Adv. Mater., 2014, 26, 8120-8125.

33 G. Polupan and T. V. Torchynska, Thin Solid Films, 2010, 518, S208-S211.

34 Z. Wei, X. Peng, L. Yang, L. Heng and H. Wen, J. Inorg. Mater., 2014, 29, 1093-1098.
35 X. Jian, B. Wu, Y. Wei, S. X. Dou, X. Wang, W. He and N. Mahmood, ACS Appl. Mater. Interfaces, 2016, 8, 61016109.

36 G. Ma, Y. Duan, Y. Liu and S. Gao, J. Mater. Sci.: Mater. Electron., 2018, 29, 17405-17415.

37 H. Pang, R. P. Sahu, Y. Duan and I. K. Puri, Diamond Relat. Mater., 2019, 96, 31-43.

38 L. Huang, Y. Duan, X. Dai, Y. Zeng, G. Ma, Y. Liu, S. Gao and W. Zhang, Small, 2019, 1902730.

39 H. Pang, A. M. Abdalla, R. P. Sahu, Y. Duan and I. K. Puri, J. Mater. Sci., 2018, 53, 16288-16302.

40 Y. Duan, Y. Liu, Y. Cui, G. Ma and W. Tongmin, Prog. Org. Coat., 2018, 125, 89-98.

41 W. Duan, X. Yin, F. Ye, Q. Li, M. Han, X. Liu and Y. Cai, J. Mater. Chem. C, 2016, 4, 5962-5969.

42 D. Ding, Y. Wang, X. Li, R. Qiang, P. Xu, W. Chu, X. Han and Y. Du, Carbon, 2017, 111, 722-732. 